\title{
Route of Delivery for Term Breech Presentation; Vaginal Versus Caesarean Section; Comparative Analysis;
}

\author{
Dr Pradeep M R ${ }^{1}$ Dr lalitha shivanna ${ }^{2}$
}

\begin{abstract}
: route of delivery for term breech presentation either by abdominal route or vaginally is a dilemma in obstetric practice. To asses mode of delivery influencing on neonatal outcome, We conducted a prospective study done in department of obstetrics and gynecology at mandya institute of medical sciences for one and half years. Out of 273 term breech presentations 134 met our criteria. $72.3 \%$ had successful assisted breech delivery. vaginal breech delivery was associated with significantly low Apgar score $(<7)$ at birth,compared to caesarean births. There is no significant difference in neonatal mortality or maternal mortality between two groups. Assisted breech delivery can be a route of choice in selected patients in a low resource set up.
\end{abstract}

\section{Introduction}

Breech presentation constitutes about $3-4 \%$ of term pregnancies. ${ }^{(1)}$ Management of breech delivery is a high risk compared to cephalic presentation with respect to fetal morbidity and mortality. Breech at term can be managed by external cephalic version, vaginal breech delivery, or by caesarean section.

Term breech trial(TBT) (Hannah et al 2000) ${ }^{(2)}$ largest multicentre randomized clinical trial published in 2000, was to determine safest mode delivery for breech presentation. The report showed there is a significant difference in perinatal mortality, neonatal mortality and serious neonatal morbidity is $1.6 \%$ versus $5.0 \%$ between caesarean section (CS) and vaginal breech delivery(VBD), but there is no change in maternal mortality or serious maternal morbidity.

With this most of experts recommended planned CS for breech presentation than VBD. . Several other studies (kumari and grundsell $2004^{(3)}$, alarab et al $2004^{(4)}$,Doyle et al $2005^{(5)}$ showed no increased risk in perinatal morbidity or mortality either by vaginal or by caesarean section.

Further TBT has its own limitations,

1) Case selection and intrapartum management was not proper

2) Skill worker in assisted breech delivery not defined ${ }^{(6)}$

Cochrane database revealed External cephalic version is helpful if it is done near term (34-36weeks). It may not be so successful if it is done after 37 weeks $^{(7)}$.

With this in mind, we conducted a study for one and half years from June 2002 to dec 2013 and offered vaginal delivery for breech presentation in selective population.

\section{Material and methods}

This was a prospective study done in department of obstetrics and gynecology at mandya institute of medical sciences from June 2012 to dec 2013.

\section{Inclusion criteria;}

1) frank/complete breech presentation

2) adequate maternal pelvis

3) no fetal anomalies on ultrasound examination

4) adequate amniotic volume

5) gestational age more than 37 weeks

Exclusion criteria;

1) any presentations other than frank / complete breech

2) neutral attitude of head/extension of head attitude

3) cord presentation

4) fetal growth restriction/ fetal macrosomia

5) inadequate maternal pelvis

6) fetal anomaly

7) breech with oligomnios

8) breech with previous uterine scar 


\section{Labor management;}

a) clinical examination at the time of labour, for the type of breech , adequacy of pelvis

b) Emergency ultrasound examination for type of breech, amniotic volume, attitude of head, and estimated fetal weight.

c) Continuous electronic monitoring of fetal heart rate in both first and second stage of labour.

d) Second stage of labor not allowed more than $60 \mathrm{~min}$

e) No induction of labour. Only augmentation of labour with Oxytocin.

f) Progress of labour is monitored every two hours by pelvic examination

g) An presence of obgyn specialist experienced in assisted breech delivery, conducted at least 25 VBD under supervision

h) An assistance should be present during delivery to apply suprapubic pressure to favour flexion of head

i) Maternal pushing efforts were encouraged in second stage

j) No fetal traction. Manipulation of fetus only after delivery of umbilicus. Spontaneous breech delivery is acceptable.

k) Nuchal arms may be reduced by lovset manevouer

1) Fetal head delivery is conducted by mauriceau-smellie-viet manevouer

m) Written and informed consent is taken after explaining risks and benefits of trial of labour and caesarean section.

\section{Results}

In the period of one and half years there were 8969 deliveries conducted in our hospital, of these 273 were term breech presentation with the incidence of $3.04 \%$.

134 breech pregnancies met our inclusion criteria, and were offered trial of labour.

Mean age of study is $23.35+/ 3.6$ years with the range from $18-36$ years.

Table 1 showing gravidity and successful VBD

\begin{tabular}{|l|l|l|l|}
\hline & $\begin{array}{l}\text { Gestational age in } \\
\text { weeks }\end{array}$ & VBD & $\begin{array}{l}\text { Failed VBD, underwent } \\
\text { Emergency LSCS }\end{array}$ \\
\hline Primigravida & $38.01+2.77$ & $51(67.1 \%)$ & $25(32.9 \%)$ \\
\hline Multigravida & $37.77+2.86$ & $46(79.3 \%)$ & $12(20.7 \%)$ \\
\hline TOTAL: & & $97(72.3 \%)$ & $37(27.7 \%)$ \\
\hline
\end{tabular}

Among 134 pregnancies 76 were nullipara and 58 were Multigravida with term pregnancy. Among Primigravida 51(67.1\%) had successful vaginal deliveries, among multi 46(79.3\%) had successful vaginal delivery. average VBD is around $72.3 \%$.

Table 2: showing average maternal age, gestational age, Apgar score in vaginal delivery and in caesarean section

\begin{tabular}{|l|l|l|l|l|l|}
\hline & Vaginal delivery & $\begin{array}{l}\text { Emergency } \\
\text { LSCS }\end{array}$ & $\begin{array}{l}\text { Elective } \\
\text { LSCS }\end{array}$ & F- Value & P-Value \\
\hline Maternal age(year) & $23.17+3.72$ & $23.57+3.58$ & $23.17+4.49$ & 0.75 & $0.602(\mathrm{NS})$ \\
\hline Gestational age(week) & $37.06+3.34$ & $38.80+1.79$ & $38.61+1.28$ & 14.88 & $<0.001(\mathrm{~S})$ \\
\hline Fetal weight(gram) & $2420.58+581$ & $2711.15+506$ & $2728.89+390$ & 10.00 & $<0.000063(\mathrm{~S})$ \\
\hline \multicolumn{2}{|l|}{} \\
\hline $\begin{array}{l}5 \quad \text { minute Apgar } \\
\text { score }(<7)\end{array}$ & 20 & 04 & 02 & & \\
\hline Admission to NICU & 08 & 01 & Nil & & \\
\hline $\begin{array}{l}\text { Congenital } \\
\text { malformation. }\end{array}$ & 07 & -- & -- & & \\
\hline
\end{tabular}

Gestational age and fetal weight are significantly higher in emergency and elective CS than assisted breech delivery.

There were 24 breech deliveries with poor Apgar score $(<7)$ at $5 \mathrm{~min} .20$ among VBD and 04 with emergency caesarean. 09 babies admitted to NICU for observation

Three babies stayed more than five days in NICU.

One baby had humerus fracture in assisted breech delivery. one baby with assisted breech delivery died with sepsis after 14days of NICU admission .

We encountered seven anomalous babies with breech presentation, six of them had neural tube defect(meningocele, meningomyelocele, spina bifida and hydrocephalous,) 
Table 3 showing failed VBD underwent emergency CS with indication

\begin{tabular}{|l|l|l|}
\hline & Primigravida (\%) & Multigravida (\%) \\
\hline Breech with Stationary labour & $16(64 \%)$ & $07(58 \%)$ \\
\hline Breech with arrest in $2^{\text {nd }}$ stage. & $05(20 \%)$ & $01(8 \%)$ \\
\hline Breech with Fetal distress & $04(16 \%)$ & $04(34 \%)$ \\
\hline Total & 25 & 12 \\
\hline
\end{tabular}

Most comman indication for failed VBD is stationary labour both in primi and multigravida

Table 4 showing breech presentation not met inclusion criteria underwent elective CS.

\begin{tabular}{|l|l|l|}
\hline & Number & Percentage \\
\hline Breech with oligomnios/PROM & 48 & 35 \\
\hline Breech with previous LSCS & 28 & 20 \\
\hline Breech with FPD & 25 & 18 \\
\hline Complicated breech & 13 & 09 \\
\hline $\begin{array}{l}\text { Medical disorders and other conditions/not } \\
\text { given consent }\end{array}$ & 25 & 18 \\
\hline
\end{tabular}

Most common indication among excluded pregnancies was breech with oligomnios and breech with previous caesarean section.

\section{Discussion}

In our study incidence of breech at term is $3.04 \%$ is comparable to other studies $(3-4 \%$ in Hickok et al, $1992^{(1)}$ fawole et al., $2001^{(8)}$

In our study average successful vaginal breech delivery is $72.3 \%$ which is almost similar to other studies reported before ${ }^{(9,10)}$. We had $79.3 \%$ of multipara delivered vaginally, compare to $67.1 \%$ in primigravida, indicating multiparous women had more chances of vaginal breech delivery than nulliparous women.

The main indication for caesarean section was stationary labour followed by fetal distress.

Labour was considered stationary, if vaginal findings during an interval of four hours did not show any progress in cervical dilatation or descent of breech ${ }^{(3)}$ In these cases vaginal delivery was abandoned and delivery was carried out by caesarean section.

In second stage of labour if delivery failed to occur in sixty minutes, these cases also considered as stationary labour and delivery was done by caesarean section.

Rigid cervix and poor perineal distention may be the reasons for stationary labour. A cervix is called rigid if it not become soft and did not dilate normally despite good uterine contractions.

In our study we encountered 23 cases of stationary labour in first stage and 06 cases of stationary labour in second stage in such cases attempt of VBD discontinued and delivered by caesarean section.

We also encountered 08 cases of fetal distress during trial of vaginal breech delivery underwent emergency caesarean section.

24 babies had poor Apgar score ( $<7)$ at birth (20 among VBD and 04 of emergency caesarean). only two babies among excluded pregnancies with breech underwent elective caesarean section had poor Apgar score. Poor apgar score $(<7)$ at birth is significantly more in VBD than in elective caesarean section similar results seen in Nkwabong Elie et al $2012^{(11)}$ one baby with VBD died after 14 days with sepsis.

We encountered seven anomalous babies with breech presentations; most common anomaly was neural tube defect.

\section{Conclusion}

Appropriate councelling is to be given to all women with breech presentation regarding mode of delivery. VBD can be a route of choice in these women. VBD is offered in selective population after doing emergency ultrasound during early labour to avoid perinatal complications. Gestational age and fetal weight both are significantly high in CS group tnan VBD. Obgyn specialist experienced in VBD is preferable during assisted breech delivery to avoid complications. Low Apgar score at birth, is significantly high in VBD than caesaren delivery,serious and significant perinatal morbidity is not seen in VBD/CS. There is a need for regular training of physicians on the skill of VBD.

\section{References}

[1]. hickok DE, Gordon DC ,Milberg JA, Williams MA, Daling JR. the frequency of breech presentation by gestational age at birth; a large population based study. Am J Obstet Gynecol1992; 166; 851-52.

[2]. mary E Hannah, walter J Hannah, Sheila A Hewson, Ellen D Hodnett, Saroj saigal,Andrew r willan, planned caesarean section versus planned vaginal birth for breech presentation at term ; a randomized multicentre trial. The lancet .2000. vol 356. 1375-83

[3]. Kumari As., Grundsell H (2004); mode of delivery for breech presentation in grandmultiparous women. Int J Gynecol Obstet 85; 234-39

[4]. Alarab M ,Regan C, O Connell M , Keane DP, O herlihy c, Foley ME (2004); singleton vaginal breech delivery at term ; still a safe option. Obstet Gynecol 103; 407-12 
[5]. Doyle NM, RiggsJW, Ramin SM, Sosa MA, Gilstrap LC $3^{\text {rd }}$ (2005); outcomes of vaginal breech delivery Am J perinatal ;22(6);325-28

[6]. Society of obstetrician and gynecologists of Canada, clinical practice guideline (2009)

[7]. Vaginal delivery of breech presentation JOGC No. 226. Jun 2009; 557-566.

[8]. Hutton EK, Hoefmeyr GJ. External cephalic version for breech presentation before term. Cochrane database of systemic Reviews 2006, Issue 1.Art no; CD000084. DOI; 10.1002/14651858.CD000084.pub2.

[9]. Fawole AO, Adeyemi AS, Adewole IF, Omingbodun AO (2001); A ten year review of breech deliveries at Ibadan Afr J Med Med sci 30(1-2);87-90.

[10]. Olivier I, pascale HA, alfredo M , planned vaginal delivery versus elective caesarean section; a study of 705 singleton term breech presentations; Br. J Obstet Gynecol 1998; 105; 710-7.

[11]. Gifford DS, Morton SC, Fiske M, Kahn K, ; a metaanalysis of infant outcomes after breech delivery; Obstet Gynecol 1995;85;104754.

[12]. Nkwabong Elie, Fomulu Joseph nelson, kouam luc, ngassa pius chanchu. Outcome of breech deliveries in Cameroonian Nulliparous women; The Journal of obstetrics and gynecology of India 2012; 62(5); 531-35. 